\title{
Floating Microparticulate Oral Diltiazem Hydrochloride Delivery System for Improved Delivery to Heart
}

\author{
Hai-feng Cheng ${ }^{1}$, Yan Feng ${ }^{2 *}$, Qun-jun Duan ${ }^{1}$, Da-Ming Jiang ${ }^{1}$ and Kai-Yu Tao ${ }^{1}$ \\ ${ }^{1}$ Department of Cardiovascular Surgery, ${ }^{2}$ Department of Cardiovascular Interventional Center, Second Affiliated Hospital \\ Zhejiang University College of Medicine, Hangzhou 310009, China \\ *For correspondence: Email: fengyan31900@gmail.com; Tel/Fax: 0086-571-87784704
}

\begin{abstract}
Purpose: To formulate and evaluate floating microparticulate oral diltiazem delivery system for possible delivery to the heart.

Method: Floating microspheres were prepared using cellulose acetate and Eudragit RS100 polymers by emulsion solvent evaporation technique. The dried floating microspheres were evaluated for micromeritic properties (flow properties, density, particle size determination) scanning as well as by electron microscopy, and in vitro floatability and drug release studies.

Results: The microspheres showed good buoyancy, good flow properties (angle of repose ranging from 24.29 to $29.02^{\circ}$ ), particle size (262.09 to $409.60 \mu \mathrm{m}$ ) and good drug loading (74.29 to $\left.92.09 \%\right)$. The microspheres were porous, hollow and spherical. All the formulations showed good in vitro controlled drug release in the range of $77.62 \pm 2.12$ to $97.50 \pm 1.04 \%$ at the end of $12 \mathrm{~h}$. Drug release was diffusion-controlled and followed zero order kinetics.

Conclusion: Microparticulate floating (gastroretentive) oral drug delivery system of diltiazem prepared using cellulose acetate and Eudragit R5100 may be an effective alternative to conventional oral tablets for cardiac drug delivery.
\end{abstract}

Keywords: $\quad$ Cardiac, Microparticulate, Drug release, Gastroretentive, Floating microspheres, Diltiazem hydrochloride

Tropical Journal of Pharmaceutical Research is indexed by Science Citation Index (SciSearch), Scopus, International Pharmaceutical Abstract, Chemical Abstracts, Embase, Index Copernicus, EBSCO, African Index Medicus, JournalSeek, Journal Citation Reports/Science Edition, Directory of Open Access Journals (DOAJ), African Journal Online, Bioline International, Open-J-Gate and Pharmacy Abstracts

\section{INTRODUCTION}

Most drugs are given by oral route as this is the most acceptable, convenient and least invasive approach for getting systemic delivery of significant therapeutic levels of drug. Drugs used in the management of cardiac diseases are to be taken for longer periods of time for maintaining blood pressure, heart beat or overall cardiac health. Unlike other routes the oral route is the most preferred route of drug administration. It is also the preferred route to deliver sustained and controlled delivery of drugs [1].
However, there are many constraints in designing oral controlled-release drug delivery systems. These include varying $\mathrm{pH}$ changes and gastric emptying time, variation in $\mathrm{pH}$ across the regions of the gastrointestinal tract (GIT) and varying absorption windows available for different drugs. Various approaches have been investigated for localizing the drug to the upper part of the GIT. These include development of gastroretentive drug delivery systems through utilizing the approaches based on buoyancy, mucoadhesion, low density, etc $[2,3]$. 
An ideal gastroretentive drug delivery system (GRDDS) localizes the drug in the upper segments of the GIT so that the drug gets maximum chance to get absorbed from the site where it is optimally absorbed [4-7].

Diltiazem hydrochloride, an $\mathrm{L}$ type calcium channel blocker, is a widely used cardiovascular drug, for the treatment of angina, essential hypertension and atrial flutter. When administered orally, frequent dosing is needed due to its short biological half-life $\left(t_{1 / 2}, 4 \mathrm{~h}\right)$ $[11,12]$. Diltiazem undergoes high hepatic first pass metabolism, and thus, bioavailability is reduced to only $40 \%$. Moreover, diltiazem shows absorption window phenomenon because it is preferentially absorbed from the upper GIT.

Therefore the present investigation aimed to formulate and evaluate gastroretentive buoyant microspheres of diltiazem hydrochloride that would localize the delivery system to the upper GIT from where it would be expected to slowly and continuously release the drug in a controlled manner leading to improved bioavailability [1315].

\section{EXPERIMENTAL}

Diltiazem hydrochloride (DTH), Polyvinyl alcohol (PVA), Tween 80 and Cellulose Acetate were procured from Sigma Aldrich USA. All other reagents used were of analytical grade.

\section{Preparation of diltiazem hydrochloride micro particles}

Microparticles loaded with DTH were prepared using an oil-in-water (ON) emulsification solvent evaporation method [16]. Six formulations were prepared using different polymers- Cellulose acetate and Eudragit RS100 (Table 1).
Drug and polymer in different proportions 1:1, $1: 2,1: 4$, were dissolved in the mixture of solvent system (dichloromethane, ethanol and isopropyl alcohol) or (ethyl acetate and acetone). The solution obtained was poured slowly into the aqueous phase consisting of $150 \mathrm{~mL}$ of $0.1 \mathrm{M}$ hydrochloric acid solution containing polyvinyl alcohol. The emulsion was continuously stirred at a speed of $800 \mathrm{rpm}$ using mechanical stirrer at room temperature for $2 \mathrm{~h}$. The microspheres were collected by decantation, while the nonfloating microspheres were discarded along with any polymer precipitates. The microspheres were dried in an oven at $50{ }^{\circ} \mathrm{C}$ for $2 \mathrm{~h}$, weighed and then stored in a desiccator at room temperature till further use.

\section{Scanning electron microscopy}

To detect the surface morphology of the microspheres, SEM of the floating microspheres was performed using Scanning Electron Microscope (Jeol of Japan Model No. 5600).

\section{Evaluation of micromeritic properties of floating microspheres}

The microspheres were characterized for their micromeritic properties, such as particle size (by optical microscopy), true density (by liquid displacement method) and flow properties (angle of repose) as reported in various previous studies [17-19].

\section{Drug loading}

Drug loading (L) was determined by the method reported by Semalty et al as in Eq 1 [17-19].

$L=(Q m / W m) 100$

where Wm is the weight of microspheres and Qm is the quantity of drug present in $\mathrm{Wm}$ of microspheres.

Table 1: Composition of the formulations

\begin{tabular}{lcccccc}
\hline Ingredient & \multicolumn{7}{c}{ Formulation $^{*}$} \\
\cline { 2 - 7 } & $\boldsymbol{F 1}$ & $\boldsymbol{F 2}$ & $\boldsymbol{F 3}$ & $\boldsymbol{F 4}$ & $\boldsymbol{F 5}$ & $\boldsymbol{F 6}$ \\
\hline $\begin{array}{l}\text { Diltiazem } \\
\text { hydrochloride }\end{array}$ & 1 & 1 & 1 & 1 & 1 & 1 \\
Cellulose acetate & 1 & 2 & 4 & - & - & - \\
Eudragit RS100 & - & - & - & 1 & 2 & 4 \\
$\begin{array}{l}\text { Polyvinyl alcohol (\% } \\
\text { w/v) }\end{array}$ & 0.05 & 0.05 & 0.05 & 0.5 & 0.5 & 0.5
\end{tabular}

${ }^{*}$ For formulations F1, F2 and F3, the solvent system was ethyl acetate: Acetone (1:1) while for formulations F4, F5 and F6, the solvent system was dichloromethane: ethanol: isopropyl alcohol (1:2:1); ratio are \% w/w of polymers; batch size was $15 \mathrm{gm}$ 


\section{In vitro floatability studies}

In vitro floatability studies on floating microspheres were carried out using USP apparatus II as reported earlier $[17,20]$. The buoyancy was calculated as in Eq 2.

Buoyancy $(\%)=W f /(W f+W s) 100$

where Wf and Ws are weights of the floating and the settled microspheres, respectively.

\section{In vitro drug release studies}

The release of DTH from the microspheres was studied in $900 \mathrm{ml}$ of $0.1 \mathrm{~N}$ hydrochloric acid using USP XXIII method with six station dissolution test apparatus type 1 at $37 \pm 0.5^{\circ}$ with a rotation speed of $100 \mathrm{rpm}$. For each formulation, a quantity of microspheres equivalent to $100 \mathrm{mg}$ of diltiazem was filled in empty capsule shells (size 00). One capsule was used in each test and placed in the basket. Samples of dissolution fluid were withdrawn at different intervals, filtered and diluted suitably and then analyzed spectrophotometrically (Double beam UV-Visible Spectrophotometer, Shimadzu, 1800, Japan) at $236 \mathrm{~nm}$.

\section{Statistical analysis}

The results were expressed as mean \pm standard deviation (SD). Statistical analysis was carried out using analysis of variance (ANOVA) on GraphPad Prism@ 4.0 (Graphpad Software Inc. San Diego, CA, USA). $P<0.05$ was considered to be significant.

\section{RESULTS}

\section{Microsphere morphology}

Scanning electron microscopy showed that the microspheres prepared using cellulose acetate and Eudragit RS100 had smooth spherical microspheres (Fig 1). Cellulose acetate microspheres exhibited a more uniform surface than those of Eudragit RS100 microspheres.
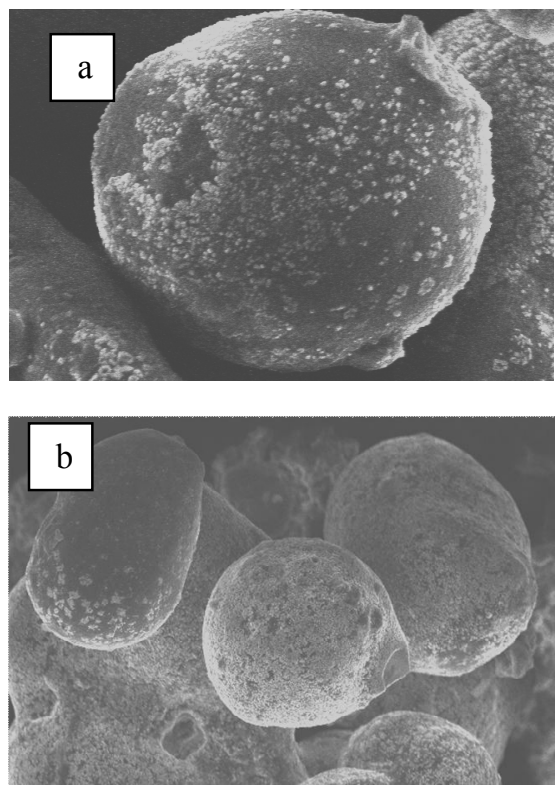

Fig. 1: SEM photographs of floating microspheres of (a) Cellulose Acetate (b) Eudragit RS100

\section{Micromeritic properties}

Table 2 reports the results of flow properties of prepared floating microspheres like angle of repose, particle size and true density.

The flow properties for the microparticles were good with angle of repose ranging from $24.29^{\circ}$ to $29.02^{\circ}$. Density was in the range of 0.729 to $0.820 \mathrm{~g} / \mathrm{cc} 3$. Particle size was in the range of 262.09 to $409.60 \mu \mathrm{m}$. Microspheres prepared with cellulose acetate (F1 - F3) were larger than those prepared with Eudragit R5100 microspheres (F4 - F6).

\section{Drug loading}

The formulations showed excellent drug loading ranging from 74.29 to $92.09 \%$ with higher loading found with cellulose acetate containing

Table 2: Characteristics of floating microspheres

\begin{tabular}{lccccc}
\hline Formulation & $\begin{array}{c}\text { Mean particle } \\
\text { size }(\boldsymbol{\mu m})\end{array}$ & $\begin{array}{c}\text { True density } \\
\left(\mathbf{g m} / \mathbf{c c}^{\mathbf{3}}\right)\end{array}$ & Angle of repose & $\begin{array}{c}\text { Buoyancy } \\
\mathbf{1 2}^{\text {th }} \mathbf{h}(\%)\end{array}$ & $\begin{array}{c}\text { Drug } \\
\text { Loading (\%) }\end{array}$ \\
\hline F1 & $341.30 \pm 1.082$ & $0.780 \pm 0.035$ & $24.29^{\circ} \pm 0.846$ & $62.8 \pm 0.940$ & $81.42 \pm 1.26$ \\
F2 & $391.52 \pm 2.136$ & $0.729 \pm 0.012$ & $24.98^{\circ} \pm 0.009$ & $79.8 \pm 1.252$ & $88.90 \pm 1.49$ \\
F3 & $409.60 \pm 3.543$ & $0.809 \pm 0.020$ & $23.80^{\circ} \pm 0.921$ & $84.4 \pm 1.486$ & $92.09 \pm 1.45$ \\
F4 & $262.09 \pm 0.446$ & $0.820 \pm 0.027$ & $26.72^{\circ} \pm 0.072$ & $60.9 \pm 1.280$ & $74.29 \pm 1.69$ \\
F5 & $274.80 \pm 2.227$ & $0.744 \pm 0.042$ & $29.02^{\circ} \pm 0.508$ & $61.2 \pm 2.422$ & $86.34 \pm 1.80$ \\
F6 & $282.04 \pm 1.294$ & $0.799 \pm 0.066$ & $26.05^{\circ} \pm 1.080$ & $68.6 \pm 2.005$ & $84.90 \pm 1.89$ \\
\hline
\end{tabular}

Results are presented as mean \pm standard deviation $(n=3)$ 


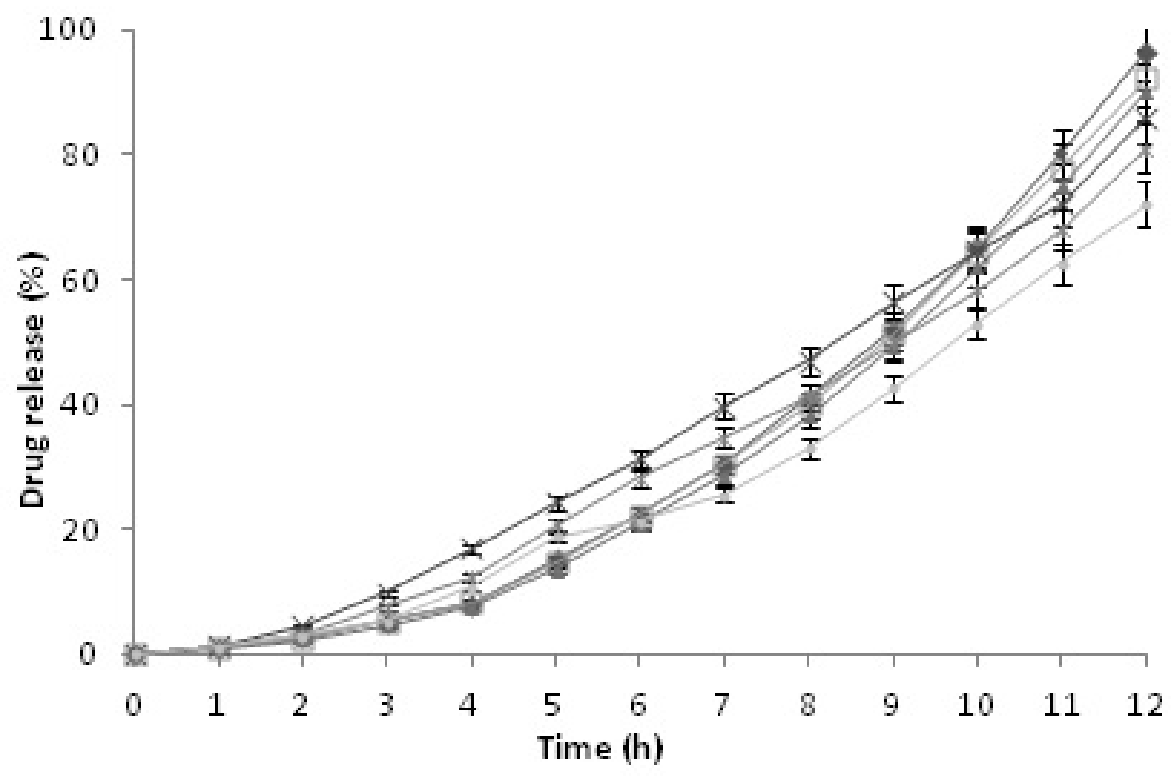

Fig 2: In vitro drug release of gastroretentive microspheres of diltiazem hydrochloride in $0.1 \mathrm{M}$ hydrochloric acid

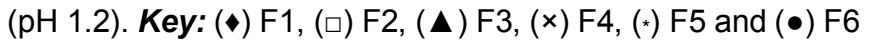

microspheres (Table 2). Formulation F3 containing cellulose acetate (with drug to polymer ratio of 1:4) showed maximum percent loading of drug (92.09\%). The rank order of Percent loading was found to be as follows - F3 $>\mathrm{F} 2>\mathrm{F} 5>\mathrm{F} 6>\mathrm{F} 1>\mathrm{F} 4$.

\section{In vitro floatability}

The microspheres showed buoyancy ranging from 60.9 to $84.4 \%$ at the end of $12 \mathrm{~h}$ (Table 2). Rank order of in vitro floatability was found to be as follows - F3 > F2 > F6 > F1 > F5 > F4.

\section{In-vitro release}

In vitro release studies of all the formulations were found to be good for a $12 \mathrm{~h}$ dissolution study (Fig 2).

Change in polymer and drug to polymer ratio showed the change in drug release. At the end of $12 \mathrm{~h}$, release was 97.50, 94.44, 91.52 , 88.24, 84.84 and $77.62 \%$ for formulations F1, F2, F3, F4, F5 and F6 respectively (Fig 2). Higuchi correlation coefficient values were $0.979,0.985$, $0.992,0.912,0.990$ and 0.990 , respectively.

\section{DISCUSSION}

Gastroretentive floating microparticles have been investigated for improving the drug release of the drugs such as DTH which are well absorbed from upper GIT. Being the drug showing absorption window phenomenon, DTH is the most suitable candidate for developing the floating drug delivery systems. In the present study, gastroretentive floating microparticles of DTH were prepared using a simple and reproducible method.

Scanning electron microscopy confirmed the hollow nature of microspheres with pores on the surface of floating microspheres, which might have imparted floating properties to the prepared floating microspheres $[16,17]$. Density was less than that of the gastrointestinal fluid, causing the microparticles to float over the gastric fluid. The presence of porous surface, internal voids and low densities of the prepared microspheres contributed to good buoyancy [17]. The average particle size of microspheres was found to be increasing with the increase in concentration of the polymer [21,22]. Drug to polymer ratio influenced almost all the physicochemical properties of the microspheres [23]. The \% drug loading was found to be increasing with drug to polymer ratio in the present study.

Drug release showed an inverse relation with concentration of polymer [24,25]. The linearity of the plot of cumulative percent of drug release versus time confirmed the zero order kinetics being followed by the formulations. The linearity of Higuchi plots indicated that the drug release from the microspheres followed the matrix diffusion process $[22,26]$. The prepared floating 
microparticles are expected to reside for longer period of time in the upper gastric region and thereby leading to better bioavailability.

\section{CONCLUSION}

Findings from the present study show that the prepared microspheres exhibited good flow, floating and drug release properties. In this regard, microsphere formulations of cellulose acetate are superior to those prepared with Eudragit RS100. Thus, gastroretentive microspheres provide a potential alternative delivery system for the delivery of diltiazem in the treatment of cardiac disease.

\section{REFERENCES}

1. Gupta H, Bhandari D, Sharma A. Recent trends in oral drug delivery: a review. Recent Patent Drug Deliv Formul 2009; 3(2): 162-173.

2. Bhavsar $D N$, Varde NM, Surendran CS, Shah $V H$, Upadhyay UMS. Advances in grdds: raft forming system a review. J Drug Delivery Ther 2012; 2(5): 123-128.

3. Bhowmik D, Chiranjib.B, Margret C, Jayakar B, Sampath KPK. Floating drug delivery system-a review. Der Pharmacia Lettre 2009; 1(2): 199-218.

4. Gangadharappa HV, Kumar PTM, Shiva KHG. Gastric floatiing drug delivery system: $A$ review. Indian $J$ Pharm Educ Res 2007; 41(4): 295-305.

5. Hoffman A, Stepensky D, Levy E, Eyal S, Klausner E, Friedman M. Pharmacokinetic and pharmacodynamic aspect of gastroretentive dosage forms. Int J Pharm 2004; 277: 141-153.

6. Kumar R, Philip A. Gastroretentive dosage forms for prolonging gastric residence time. Int $J$ Pharm Med 2007; 21(2): 157-171.

7. Ali J, Tyagi $P$, Ahuja $A$, Baboota $S$, Hasan $S$. Development and evaluation of a gastroretentive drug delivery system for the low-absorption-window drug celecoxib. PDA J Pharm Sci Technol 2007; 61(2): 8896.

8. Rao GK, Mandapalli PK, Manthri RP, Reddy VP Development and in vivo evaluation of gastroretentive delivery systems for cefuroxime axetil. Saudi Pharm J 2013; 21(1): 53-59.

9. Umamaheshwari RB, Jain S, Bhadra D, Jain NK. Floating microspheres bearing acetohydroxamic acid for the treatment of Helicobacter pylori. J Pharm Pharmacol 2003; 55(12): 1607-1613

10. Klausner EA, Lavy E, Friedman M, Hoffman $A$. Expandable gastroretentive dosage forms. J Control Release 2003; 90: 143-162.

11. Sultana $Y$, Mall S, Maurya DP, Kumar D, Das $M$. Preparation and in vitro characterization of diltiazem hydrochloride loaded alginate microspheres. Pharm Dev Technol 2009; 14(3): 321-331.
12. Das MK, Maurya DP. Evaluation of diltiazem hydrochloride-loaded mucoadhesive microspheres prepared by emulsification-internal gelation technique. Acta Pol Pharm 2008; 65(2): 249-259.

13. Semalty A, Bhojwani M, Bhatt GK, Gupta GD, Shrivastav AK. Design and evaluation of mucoadhesive buccal films of diltiazem hydrochloride. Indian J Pharm Sci 2005; 67(5): 548-552

14. Corrigan OI, Heelan BA. Characterization of drug release from diltiazem-loaded polylactide microspheres prepared using sodium caseinate and whey protein as emulsifying agents. J Microencapsul 2001; 18(3): 335-345.

15. Bayomi MA, al-Suwayeh SA, el-Helw AM, Mesnad AF. Preparation of casein-chitosan microspheres containingdiltiazem hydrochloride by an aqueous coacervation technique.Pharm Acta Helv 1998; 73(4): 187- 192.

16. Soppimath KS, Kulkarni AR, Aminabhavi TM. . Development of hollow icrospheres as floating controlled-release systems for cardiovascular drugs: preparation and release characteristics. Drug Dev Ind Pharm 2001; 27(6): 507-515.

17. Semalty $M$, Yadav S, Semalty A. Preparation and characterization of gastroretentive floating microspheres of ofloxacin hydrochloride. Int $J$ Pharm Sci Nanotech 2010; 3: 819-823.

18. Khan $A B$, Thakur RS Formulation and evaluation of mucoadhesive microspheres of tenofovir disoproxil fumarate for intravaginal use. Curr Drug Deliv 2014; 11(1): 112-122.

19. Semalty A, Semalty M. Preparation and Characterization of Mucoadhesive Microspheres of Ciprofloxacin Hydrochloride. Indian Drugs 2007; 44: 368-372.

20. Ali M, Khar R, Rahman Z. Design and evaluation of bilayer floating tablets of captopril. Acta Pharm 2006; 56(1): 49-57.

21. Fernandes M, Gonçalves IC, Nardecchia S, Amaral IF, Barbosa MA, Martins MC. Modulation of stability and mucoadhesive properties of chitosan microspheres for therapeutic gastric application. Int J Pharm 2013; 454(1): 15: 116-124.

22. Klose D, Siepmann F, Elkharraz K, Krenzlin S, Siepmann J. How porosity and size affect the drug release mechanisms from PLGA-based microparticles. Int $\mathrm{J}$ Pharm 2006; 314(2): 198-206.

23. Francisco LM, Cerquetani JA, Bruschi ML. Development and characterization of gelatin and ethylcellulose microparticles designed as platforms to delivery fluoride. Drug Dev Ind Pharm 2013; 39(11): 16441650.

24. Prabhu P, Ahamed N, Matapady HN, Ahmed MG, Narayanacharyulu $R, \quad$ Satyanarayana $D$, Subrahmanayam E. Investigation and comparison of colon specificity of novel polymer khaya gum with guar gum. Pak J Pharm Sci 2010; 23(3): 259-265.

25. Gohel MC, Sumitra $G$ M. Modulation of active pharmaceutical material release from a novel 'tablet

Trop J Pharm Res, June 2015; 14(6): 939 
in capsule system' containing an effervescent blend. J Control Release 2002; 79(1-3): 157-164.

26. Faisant N, Akiki J, Siepmann F, Benoit JP, Siepmann J. Effects of the type of release medium on drug release from PLGA-based microparticles: experiment and theory. Int J Pharm 2006; 314(2): 189-197. 